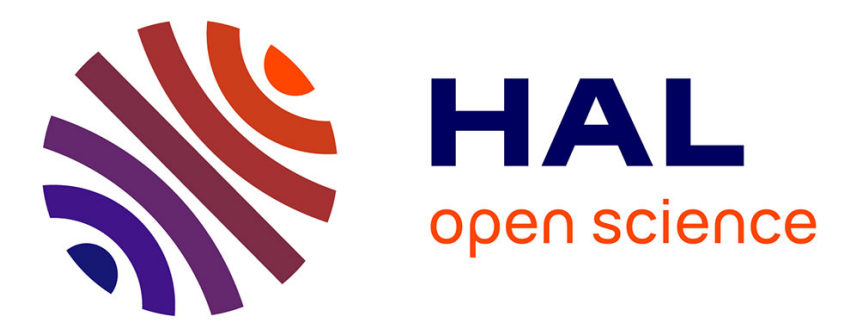

\title{
Oxytocin administration during spontaneous labor: Guidelines for clinical practice. Chapter 3: Interventions associated with oxytocin administration during spontaneous labor
}

C. Barasinski, F. Vendittelli

\section{To cite this version:}

C. Barasinski, F. Vendittelli. Oxytocin administration during spontaneous labor: Guidelines for clinical practice. Chapter 3: Interventions associated with oxytocin administration during spontaneous labor. Journal of Gynecology Obstetrics and Human Reproduction, 2017, 46 (6), pp.489-497. 10.1016/j.jogoh.2017.04.008 . hal-01653219

\author{
HAL Id: hal-01653219 \\ https://hal.science/hal-01653219
}

Submitted on 1 Dec 2017

HAL is a multi-disciplinary open access archive for the deposit and dissemination of scientific research documents, whether they are published or not. The documents may come from teaching and research institutions in France or abroad, or from public or private research centers.
L'archive ouverte pluridisciplinaire HAL, est destinée au dépôt et à la diffusion de documents scientifiques de niveau recherche, publiés ou non, émanant des établissements d'enseignement et de recherche français ou étrangers, des laboratoires publics ou privés. 


\section{Accepted Manuscript}

Title: Oxytocin administration during spontaneous labor: guidelines for clinical practice. Chapter 3: Interventions associated with oxytocin administration during spontaneous labor

Author: Chloé Barasinski Françoise Vendittelli

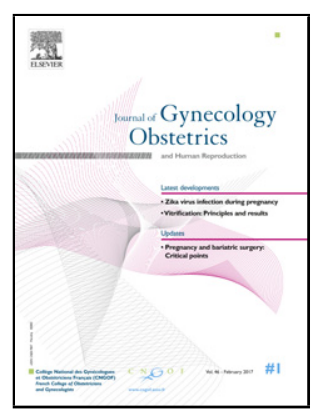

PII:

DOI: S2468-7847(17)30106-X

Reference: http://dx.doi.org/doi:10.1016/j.jogoh.2017.04.008 JOGOH 66

To appear in:

Please cite this article as: Chloé BarasinskiFrançoise Vendittelli Oxytocin administration during spontaneous labor: guidelines for clinical practice. Chapter 3: Interventions associated with oxytocin administration during spontaneous labor (2017), http://dx.doi.org/10.1016/j.jogoh.2017.04.008

This is a PDF file of an unedited manuscript that has been accepted for publication. As a service to our customers we are providing this early version of the manuscript. The manuscript will undergo copyediting, typesetting, and review of the resulting proof before it is published in its final form. Please note that during the production process errors may be discovered which could affect the content, and all legal disclaimers that apply to the journal pertain. 
Guidelines for clinical practice

Oxytocin administration during spontaneous labor: guidelines for clinical practice. Chapter 3: Interventions associated with oxytocin administration during spontaneous labor

Chloé Barasinski ${ }^{1}$, Françoise Vendittelli ${ }^{1,2}$

${ }^{1}$ Université Clermont Auvergne, CHU Clermont-Ferrand, CNRS, SIGMA Clermont, Institut Pascal, F-63000 Clermont-Ferrand, France

${ }^{2}$ AUDIPOG Sentinel Network (Association des Utilisateurs de Dossiers informatisés en Pédiatrie, Obstétrique et Gynécologie), RTH Laennec Medical University, 7 rue Guillaume Paradin, 69372 Lyon Cedex 08, France.

CORRESPONDING AUTHOR: Chloé Barasinski, CHU de Clermont-Ferrand, Hôpital Estaing, Pôle de Gynécologie-Obstétrique, Recherche Clinique en Périnatalité, 1 place Lucie et Raymond Aubrac, 63003 Clermont-Ferrand Cedex 1, France.

cbarasinski@chu-clermontferrand.fr 


\section{Summary}

Objectives. - The objective of our work was to determine the effects of co-interventions used during labor with oxytocin or for labor dystocia.

Methods. - We searched for reports of the interventions we sought to study published between 1987 and 2015, looking especially for meta-analyses and randomized trials via the Medline database and the Cochrane Library. We limited our research to studies of spontaneous labor in singleton pregnancies at term.

Results. - In the absence of labor dystocia, active management of labor is not recommended (Grade B). It is recommended that amniotomy should not be performed routinely during the first stage of labor (Grade B). In cases of labor dystocia during the active phase, an amniotomy is recommended before the administration of oxytocin (professional consensus). The encouragement of continuous support during labor is recommended (Grade B). No scientific evidence justifies the recommendation of any of the following methods for the sole purpose of limiting oxytocin use during labor: maternal position during the first or second stages of labor (grade C), immersion in a water during the first stage (grade B), intravenous infusion, oral hydration, or solid food (grade B), antenatal preparation with hypnosis sessions (grade C), use of relaxation techniques (grade C), acupuncture or acupressure (Grade B), or the use of muscle-relaxant agents (professional consensus).

Conclusions. - Few of the co-interventions studied appear to modulate recourse to oxytocin.

Key words: active management of labor; amniotomy; continuous support; first stage of labor; oxytocin. 


\section{Introduction}

Oxytocin and its contractile properties were first discovered in 1909; it was first synthesized in 1954. From then on, its use became one of several interventions often used during labor in various combinations [1]. Numerous studies rapidly reported the value of its wide use to optimize labor and delivery. In 2016, the principal indication for oxytocin during labor is labor dystocia [2].

Simultaneously and over time, different co-interventions that might act on this form of dystocia - either to prevent or treat it — have been used during labor. Moreover, other cointerventions are frequently used during labor and may (or may not) affect recourse to oxytocin. These interventions can be used routinely at the onset of labor, at different stages during the first or second stage or adapted to particular clinical situations. Although the relevance of these co-interventions has been assessed recently, some have not ever been assessed.

The objective of this work is therefore to detail the most common co-interventions used during labor to assess their impact on either labor dystocia or recourse to oxytocin.

\section{Materials and methods}

\section{Materials}

After selecting the co-interventions to be studied, we identified publications about them describing recourse to oxytocin in studies of spontaneous labor of singleton pregnancies at term. We limited our selection to studies published in English and in French between 1987 and 2015.

We looked first for meta-analyses, then randomized trials not included in the metaanalyses, and, when no randomized trials were available, other types of studies. 


\section{Methods}

We searched for articles in the Medline database and the Cochrane Library, limiting our research to "randomized controlled trial" and "meta-analysis" with the following keywords:

- "active management labor" OR "oxytocin" AND "amniotomy" NOT "induction"

- or "amniotomy" NOT "induction"

- or "continuous labor support"

- or "positions" AND "labor"

- or "water immersion" AND "labor"

- or "oral intake" AND "augmentation"

- or "labor" AND "massage"

- or "hypnosis" AND "childbirth"

- or "acupuncture" AND "childbirth"

We completed our search manually by consulting the references in the publications identified and the guidelines published on the subject by North American, British, and French professional and learned societies.

When we say that something should or should not be done, we mean to say that it is a recommendation unless a specific reason based on the clinician's experience, the patient's individual characteristics, or the organization of care overrides it. Should essentially means must unless there is a strong reason not to, and should not means do not, unless there is a strong reason to do it. 


\section{Results}

\section{Active management of labor}

\section{Definition of active management of labor}

Active management of labor is a set of interventions intended to limit the duration of labor and thereby, in particular, reduce the number of cesarean deliveries. It was first described by O'Driscoll in Ireland in the 1970s [3]. It includes 7 components:

- $\quad$ strict criteria for the diagnosis of labor

- $\quad$ strict monitoring of progress in labor (e.g., by plotting on a partogram)

- $\quad$ strict criteria for identifying slow progress and fetal compromise

- peer review of assisted deliveries

- one-to-one support in labor (continual presence of a nurse during labor)

- routine amniotomy (artificial rupture of the amniotic membranes)

- the use of the intravenous drug oxytocin only after membrane rupture, if dilation remains $<1 \mathrm{~cm} / \mathrm{h}$

O'Driscoll et al. studied active management of labor at the National Hospital of Dublin, in 1968 and 1972, in two cohorts of 1000 nulliparas [2,3], with overall percentages of cesarean deliveries of $4 \%$ and $5.2 \%$, respectively. In their 1968 cohort, $20.4 \%$ of the women had interventions to accelerate labor (amniotomy and/or oxytocin) [3]. In 1972, 55\% of the women received oxytocin [4].

Because subsequent trials of the "package" of active management of labor used different groups of interventions, it is difficult to compare them. Moreover, the interventions in the control groups also varied between the studies as well as within them (e.g., expected speed of cervical dilation). 
We identified four meta-analyses grouping together randomized or quasi-randomized trials published between 1998 and 2013 on this topic [5-8]. The first meta-analysis focused on the combined effects of an early amniotomy and early prescription of oxytocin on the risk of cesareans in nulliparas. It included 3 "therapeutic" trials of women with inadequate progress in labor (defined by labor dystocia with lack of progress in dilation for 2 hours or a dilation speed $<0.5 \mathrm{~cm} / \mathrm{h}$ for more than 4 hours or delay in the active phase of labor), while 7 trials took place among women with normal labor (preventive approach) [5]. Considering all of the studies together, the authors found no statistically significant difference in the cesarean risk in the intervention group compared with the control group $(n=5111$, OR $0.88,95 \%$ CI $0.7-1.1)$. When they stratified the analysis according to preventive or treatment approaches, they still did not find a statistically significant difference between the two groups for cesarean deliveries (preventive approach: $\mathrm{n}=5002$, OR $0.90,95 \%$ CI $0.7-1.1$; treatment approach: $\mathrm{n}=$ 109, OR $0.57,95 \%$ CI: $0.2-1.4$ ). Nor did this meta-analysis find any reduction in maternal or neonatal morbidity that might support such a care policy. The co-interventions, the quality of the randomization, and the timing of randomization relative to oxytocin administration also differed from study to study (LE2).

This first meta-analysis was updated in 2013 in the Cochrane Database [6], which excluded the studies with small sample sizes $[9,10,11]$ and the two unpublished trials (Labrecque et al., Verkuyl et al). It also included 9 supplementary studies [8, 12-23]. This meta-analysis (14 studies, 8033 women), unlike the first one [5], concerned both nulliparous and parous women, but had the same objectives [6]. The authors found a non-significant trend towards a reduction in the risk of cesarean delivery in the overall intervention group $(n=8033$, RR 0.89, 95\% CI 0.79-1.01). The same was true when the analysis was limited to studies for which the intervention was intended as treatment. On the other hand, when used for preventive purposes, the intervention was associated with a modest reduction in the number of 
cesareans $(\mathrm{n}=7753$, RR $0.87,95 \%$ CI $0.77-0.99)$. Nonetheless, the number of women needed to treat to prevent one cesarean was 65. A policy of early amniotomy and oxytocin was associated with a shorter duration of labor $(n=2671$, mean difference: -1.28 h, $95 \%$ CI: -1.97 to -0.59). This result was not observed in the treatment group. No other statistically significant effect was observed for either maternal or neonatal outcomes (LE2).

It must be noted that this meta-analysis, like the preceding one [5], included studies that did not always use optimal techniques or timing of randomization. Two studies did not distinguish nulliparous from parous (primiparous and multiparous) women, and no study focused solely on nulliparas. The interval to oxytocin administration in the control group varied considerably between studies. Moreover, the contrast between the two groups was reduced by the performance of amniotomy in the control as well as intervention groups in all the trials. In some studies, the two groups had fairly similar percentages of women receiving oxytocin [19, 20, 24-26]. Most of the studies concerned the "complete package" of active management of labor (including continuous support by a professional throughout labor). It is therefore impossible to isolate the effect of either amniotomy or oxytocin alone compared with the entire package.

Another Cochrane meta-analysis [7] examined only complete active management of labor packages and found results very close to those of the preceding meta-analysis. It used 7 of the 14 studies included in [6] above and found a modest but not significant reduction in the number of cesareans in the active management group ( $\mathrm{n}=5390$, RR $0.88,95 \%$ CI $0.77-1.01$ ) [7] (LE2). Finally, the meta-analysis by Wei et al. [6] also included the meta-analysis published in 2000 by Saddler [8] (LE2). None of these meta-analyses found any other comorbidity associated with one management rather than another. 
Overall, routine active management of labor, defined by an early amniotomy and oxytocin administration during spontaneous labor, does not reduce the cesarean rate (LE2). In the absence of labor dystocia, active management of labor is not recommended (grade B).

We note here that according to the guidelines for abnormal labor defined in [27], labor dystocia can be defined by a dilation speed $<1 \mathrm{~cm} / 4 \mathrm{~h}$ at the beginning of the active phase of the first stage and $<1 \mathrm{~cm} / 2 \mathrm{~h}$ above $7 \mathrm{~cm}$ of dilation.

\section{Amniotomy}

\section{Pathophysiologic effect of amniotomy on labor}

During labor, rupture of the membranes appears to increase prostaglandin synthesis, which in turn increases the synthesis of endogenous oxytocin. This may therefore increase the strength of uterine contractions and accelerate cervical dilation [28]. Nonetheless, amniotomy may also increase the risk of fetal heart rate abnormalities by compression of either the cord or the fetal head, due to repeated uterine contractions; this does not however appear to have a harmful effect on neonatal outcome [29].

Because rupture of the membranes can improve uterine contractile action, several learned societies include in their criteria for labor dystocia or failure of dilation to progress that they should be diagnosed only after the membranes have ruptured. The American College of Obstetricians and Gynecologists (ACOG) defines arrest of labor in the first stage to require ruptured membranes and either 4 hours or more of adequate uterine activity or 6 hours or more of inadequate uterine activity [30]. The National Institute for Health and Care Excellence (NICE) recommends proposing amniotomy to women with intact membranes and 
prolonged labor, that is, dilation $<2 \mathrm{~cm} / 4 \mathrm{~h}$. An oxytocin infusion should be offered if the prolonged labor is then confirmed [31].

\section{Routine amniotomy vs conservative approach}

We identified three meta-analysis of randomized trials involving an isolated amniotomy at the onset of labor $[28,32,33]$. The first meta-analysis by Brisson-Carroll et al. precedes those in the Cochrane database, which consider all of the studies analyzed by them $[28,32,33]$. We will therefore not review it here.

The other two come from the Cochrane Database and look at the effect of amniotomy on the duration of labor by comparing a routine amniotomy alone at the onset of labor vs a conservative approach towards the amniotic sac among both nulliparous and parous women [28, 33]. The 2006 meta-analysis by Fraser et al. [33] was updated by Smyth et al. in 2013 [28]. Fraser et al. examined 9 randomized trials and concluded that an early amniotomy was associated with significant reductions in the duration of labor (between 60 and $120 \mathrm{~min}$ ) (LE2) and in the percentage of 5-minute Apgar scores $<7$ (OR 0.54, 95\% CI 0.30-0.96) and with a non-significant increase in the cesarean risk (OR 1.26, 95\% CI 0.96-1.66) (LE2). They also found a significant diminution in oxytocin use (OR 0.79, 95\% CI 0.67-0.92) (LE2).

The meta-analysis by Smyth et al. included 15 studies [28]. It also found a significant reduction in oxytocin use in the amniotomy group $(\mathrm{n}=4264$, RR $0.72,95 \%$ CI $0.54-0.96)$ (LE2). In the subgroup analysis, this effect was observed only among parous women $(\mathrm{n}=533$, RR $0.43,95 \%$ CI $0.30-0.60$ ). This result is based on the randomized trial by Mikki et al., who compared a routine amniotomy at the onset of labor to a policy of selective amniotomy [34]. They found that dystocia, defined by no change in cervical dilation for 2 hours, was less frequent in the amniotomy group $(\mathrm{n}=533, \mathrm{RR} 0.35,95 \% \mathrm{CI} 0.22-0.54)$ and that they therefore used oxytocin less often ( $\mathrm{n}=533$, RR $0.34,95 \%$ CI 0.22-0.52). Nonetheless, Smyth et al. 
concluded that amniotomy is not indicated during labor because they, unlike Fraser et al. [33], found that it did not reduce the duration of labor [28]. They did find, like Fraser et al., a nonsignificant increase in the cesarean risk (RR 1.27, 95\% CI 0.99-1.63) but also a significant reduction in oxytocin use (RR $0.72,95 \%$ CI $0.54-0.96)$. We must nonetheless note that the 15 studies identified by Smyth et al. included 9 randomized trials already included in the review by Fraser et al., 3 new randomized trials [34-36], and 3 randomized trials that Fraser et al. had excluded for methodological reasons (non-comparable groups, loss to follow-up between randomization and delivery, etc.) [37-39]. Moreover, in its 2014 guidelines, NICE [31] used the review by Fraser et al. from 2007 [33] and not the last Cochrane meta-analysis by Smyth et al. [28].

A recent randomized trial compared routine amniotomy at the onset of labor (intervention group) to a restrictive amniotomy policy in nulliparous women (control group) $(n=300)[40]$. Too new to have been included in the meta-analysis by Smyth et al., it found a significant reduction in the number of cesareans $(P<0.001)$ after routine amniotomy at the onset of labor. The percentage of cesareans in the control group was, however, very high (39.3\%). This study did not examine use of oxytocin. The duration of labor was 9.9 hours (SD $\pm 1.0 \mathrm{~h}, P<0.001)$ in the control group, and women were included at $1 \mathrm{~cm}$ of dilation (although the amniotomy was performed at a mean of $4 \mathrm{~cm}$ in the intervention group) (LE2).

In summary, a routine early amniotomy reduced oxytocin use during labor but did not improve maternal or neonatal outcomes and may even have increased recourse to cesareans (LE2).

\section{Amniotomy vs expectant management for labor dystocia}

We found only one small randomized trial comparing an amniotomy with expectant 
management (watchful waiting) for labor dystocia, defined as a lack of progress in dilation for 2 hours or by crossing the action line on the partograph by 2 lines (the action line was parallel to the alert line $[=1 \mathrm{~cm} / \mathrm{h}]$ but 3 hours to its right) [12]. Inclusion stopped at half the planned sample size after three years, because inclusion speed was slower than expected. The authors therefore did not have sufficient power to reach a conclusion about some objectives (amniotomy group=20, expectant group=19). No difference was found for oxytocin use or for obstetric or neonatal outcomes (e.g., cesareans, operative vaginal deliveries, umbilical pH, or Apgar scores). Note that $55 \%$ of the women in the amniotomy group received oxytocin 4 hours after randomization, and $63.1 \%$ of those in the expectant group 8 hours after randomization (LE3).

The current scientific data do not provide enough information to reach a conclusion about the value of amniotomy in labor dystocia (LE3).

\section{Amniotomy vs oxytocin for labor dystocia}

A randomized trial $(n=212)$ by Nachum et al. [16] compared 4 groups: a control group and 3 intervention groups (amniotomy alone, oxytocin alone, and amniotomy+oxytocin). The women in the intervention groups all had a prolonged latent phase $(>20 \mathrm{~h}$ for nulliparas and $>14 \mathrm{~h}$ for parous women). The control group comprised women admitted during the latent phase who subsequently progressed normally through labor without intervention. The authors found no significant difference between the amniotomy-only or oxytocin-only groups for duration of labor or obstetric or neonatal outcomes, that is, cesareans, operative vaginal deliveries, immediate postpartum hemorrhages (PPH), or 5-minute Apgar scores. Similarly, they did not find significant differences among the nulliparous women in the subgroup analysis. Nonetheless, the small number of women in each group (21 vs 20) meant the power to find significant results was low. Among the parous women $(n=148)$, the authors found a shorter total duration of labor in the amniotomy-only group than in the oxytocin-only group 
(352 $\min \pm 320$ vs $457 \min \pm 305, P=0.008$ ). This difference was not found between the amniotomy-only and control groups. There was no difference between the groups for the duration of the second stage of labor. We note the absence of details about the use of other cointerventions for each of these two interventions (amniotomy and oxytocin) (LE2).

As a first-line treatment, in women with labor dystocia, use of oxytocin rather than an amniotomy did not improve either maternal or fetal outcomes (LE2).

\section{Amniotomy vs amniotomy+oxytocin for labor dystocia}

In the randomized trial above, as described, the authors also compared the control group without labor dystocia with two groups of women in a prolonged latent phase $(>20 \mathrm{~h}$ for nulliparas and $>14 \mathrm{~h}$ for parous women): the amniotomy-only group and a group receiving both amniotomy+oxytocin $(n=211)$ [16]. They did not find a significant difference between the groups for obstetric or neonatal outcomes (e.g., cesareans, operative vaginal deliveries, immediate PPH, and 5-minute Apgar scores). The duration of the first stage of labor was significantly shorter in the amniotomy+oxytocin group than in the amniotomy-only group ( $283 \pm 233 \mathrm{~min}$ vs $403 \pm 327 \mathrm{~min}, P=0.03$ ). In the subgroup analysis, the authors reached the same conclusions about the duration of the first stage of labor for nulliparas $(P=0.02)$, but this analysis again compared small numbers of women in each group (21 vs 16). For the parous women $(n=151)$, the duration of first stage of labor did not differ between the two treatment groups, nor did the second-stage duration (LE2). We again note the lack of detail about the use of other co-interventions for the study groups (amniotomy and oxytocin).

The NICE guidelines also perform a meta-analysis of three randomized trials comparing an amniotomy vs amniotomy+oxytocin in women with labor dystocia $[10,12,41]$. They found no difference for maternal or neonatal outcomes, considering in particular the percentage of cesareans ( 3 studies, $n=1027$; RR 0.82 , 95\% CI $0.47-1.40$ ) and the proportion of 
children with a 5-minute Apgar score $<7$ (2 studies, $\mathrm{n}=101$, RR 0.95, 95\% CI 0.13-7.09) (LE2).

As a first-line treatment for labor dystocia, the combination of an amniotomy and an oxytocin infusion, compared to an amniotomy alone, does not improve maternal or neonatal outcomes (LE2).

\section{Oxytocin vs amniotomy+oxytocin for labor dystocia}

Rouse et al. conducted a randomized trial $(\mathrm{n}=118)$ to compare a policy of oxytocin+amniotomy vs oxytocin alone in cases of labor dystocia, defined by dilation of $1 \mathrm{~cm}$ or less in $2 \mathrm{~h}$ in all women [42]. The authors found no difference in obstetric or neonatal outcomes (cesareans, umbilical artery $\mathrm{pH}$, and neonatal infection) or in the duration of labor (LE2). The number of maternal infections (chorioamnionitis and/or endometritis) increased significantly in the amniotomy group ( $0 \%$ for oxytocin-only vs $12 \%, P=0.01)$; the women were monitored with internal tocodynamometry and fetal scalp electrodes.

The study by Nachum et al., mentioned above, compared an oxytocin-only group with an oxytocin+amniotomy $(\mathrm{n}=143)$ and reported no significant differences between the groups for obstetric or neonatal outcomes (e.g., cesareans, operative vaginal deliveries, immediate PPH, and 5-min Apgar scores) [16]. The durations of the first stage of labor and of total labor were significantly shorter in the amniotomy+oxytocin group than in the amniotomy-only group ( $283 \pm 233 \mathrm{~min}$ vs $463 \pm 313 \mathrm{~min}, P=0.001$ ). The authors reached the same conclusion about the duration of the first stage of labor for the nulliparas in the subgroup analysis ( $P=0.01)$, but again, as in other parts of this study, the comparison involved only a small number of women in each group (20 vs 16). The first stage of labor and the total duration of labor were also shorter among the parous women $(n=107)$ in the amniotomy+oxytocin group than in the oxytocin-only group $(P=0.001)$. There was no difference between the groups for the second-stage duration (LE2). 
As a first-line treatment of women with labor dystocia, the combination of amniotomy+oxytocin does not improve maternal or neonatal outcomes compared to an amniotomy alone (LE2).

\section{Conclusions about amniotomy}

On the whole, it is recommended that amniotomy should not be performed routinely during the first stage of labor (Grade B). In cases of labor dystocia during the active phase, an amniotomy is recommended before the administration of oxytocin (professional consensus). Once an amniotomy has been performed, oxytocin should not be administered for at least one hour, to assess the effect of the amniotomy on dilation speed (professional consensus).

\section{Continuous support during labor}

Continuous support during labor implies the permanent presence of a third person, who provides emotional support to the woman in labor (continuous presence, reassuring attitude), information about the progress of labor, and advice to facilitate labor and furnish comfort to her (e.g., massage, bath/shower) [43]. Continuous support also plays a role in reducing pain during the progression of labor. It appears to be involved with the emotional component of pain associated with uterine contractions [44]. This support during labor can be provided, according to the studies, by healthcare professionals (midwives and nurses) or others (partner, family member, or individuals who are not hospital employees and have no personal relationship to the laboring woman, such as a doula).

This continuous support during labor may be associated with fewer maternal and neonatal complications since it appears to increase the number of spontaneous deliveries by reducing the risk of cesarean and instrumental deliveries. Moreover, it may reduce the risk of a low 5-minute Apgar score [43]. The World Health Organization recommends continuous support in its guidelines for improving obstetric outcomes [45]. NICE 
recommends implementation of continuous support by a midwife regardless of where delivery is being managed [31]. Other learned societies of obstetricians (ACOG and SOGC) also recommend the provision of continuous support during labor [30, 46].

From 1996 through 2014, four meta-analyses assessed its impact on oxytocin use during labor $[43,44,47,48]$. The Cochrane database meta-analysis looked at the effects of continuous support for women (non-parous and parous) during labor compared with usual management [43]. It concluded that the women receiving continuous support during labor had a higher likelihood of spontaneous vaginal delivery (RR 1.08, 95\% CI 1.04-1.12]) and shorter durations of labor (mean difference: $0.58 \mathrm{~h}, 95 \% \mathrm{CI}-0.85$ to -0.31 ). They also had a lower risk of a cesarean (RR 0.78, 95\% CI 0.67-0.91]), an operative vaginal delivery (RR $0.90,95 \%$ CI 0.85-0.96), or a newborn with a low 5-minute Apgar score (the definition of which is imprecise, given that is defined as "that defined in the included studies") (RR 0.69, 95\% CI 0.50-0.95). Of the 22 trials included, 15 measured the effect of continuous support on recourse to oxytocin. Continuous support during labor had no statistically significant effect on oxytocin administration ( $\mathrm{n}=12,620$, RR $0.97,95 \%$ CI $0.91-1.04)$ (LE2). The subgroup analyses showed that continuous support by a hospital staff member had a moderately negative impact on oxytocin use during labor ( $\mathrm{n}=9561, \mathrm{RR} 1.06,95 \% \mathrm{CI} 1.01-1.11])$. If this support, however, came from a person present solely to provide support, who was not a member of the woman's social network or of the hospital medical team, was experienced in providing labor support, and had at least a modest amount of training, oxytocin use during labor fell ( $\mathrm{n}=2041$, RR 0.69, 95\% CI 0.50-0.94) (LE2). It should be noted that although the methodological quality of these studies seems correct, the moment that continuous support began varies between the studies. Moreover, the analysis did not distinguish between continuous or quasi-continuous support. The intervention studied was therefore not uniform in 
all studies. Finally, a member of the medical team involved in continuous support could be a midwife, a nurse, or a student midwife.

In their second meta-analysis, Chaillet et al. looked at non-pharmacological approaches to pain management during labor compared with usual care [44]. These nonpharmacological approaches were divided into three categories according to their mechanism of action: the gate control theory of pain with gentle stimulation of the painful area (e.g., bath, massage, and heat), diffuse noxious inhibitory control by painful stimulation during contractions (e.g., acupressure, ice, and injection of small amounts of sterile water), and control of the higher centers of the central nervous system by mental stimulation (such as relaxation, yoga, and continuous support). The authors described their results according to the mechanism of action against pain and the approach used in the study. Of 57 studies considered in this meta-analysis, 14 focused on continuous support during labor $(n=12,401)$. Here, the continuous support was provided by a doula, a nurse, or a midwife. The authors found that oxytocin use increased during standard management, compared with continuous support during labor $(\mathrm{n}=12,401, \mathrm{RR} 1.27,95 \%$ CI, 1.02-1.58]) (LE2). Nonetheless, these studies did not clearly define the intervention tested.

The other two meta-analyses were that of Zhang et al., published in 1996, and that of Scott et al. in 1999. These two studies provided no additional information. All of the studies selected are summarized in the Cochrane database meta-analysis, except for the study by Sosa et al., which was excluded because of important biases (post-hoc exclusion for prolonged labor or need for a co-intervention such as oxytocin during labor) [47, 48, 49]. 
Overall, the contradictory results do not enable us to reach any definitive conclusion about the effect of continuous support during labor on oxytocin use (LE3), although this practice does appear to improve maternal and neonatal outcomes (LE2). The encouragement of continuous support during labor is recommended (grade B).

\section{Other interventions modulating oxytocin use}

\section{Maternal positions and walking during the first stage of labor}

A single Cochrane database meta-analysis, published in 2013, has approached this subject [50]. It included 25 randomized or quasi-randomized trials and examined the effect of vertical positions (walking, standing, seated, on knees, with bended knees, and on all fours) vs horizontal positions (lying down, semi-seated, and lateral) during the first stage of labor, among nulliparous and parous women. For the women without epidural analgesia, there was a modest, non-significant reduction in oxytocin use during labor among the women using vertical compared with horizontal positions ( $\mathrm{n}=1826$, RR $0.89,95 \%$ CI $0.76-1.05)$. Among the women with epidural analgesia, the authors found no difference in oxytocin use during labor ( $\mathrm{n}=1161, \mathrm{RR}=0.98,95 \% \mathrm{CI} 0.90-1.07)$. Nonetheless, the quality of the randomization of the studies is questionable. Moreover, the co-interventions used differed from study to study according to the positions used and were sometimes described in very little detail. Finally, the regimen and methods of administration and the indications for oxytocin use were not specified (LE3).

On the whole, the use of a vertical or horizontal position during the first stage of labor does not appear to affect recourse to oxytocin (LE3).

\section{Maternal positions during the second stage of labor}

Theoretically, vertical positions may reduce oxytocin use during the second stage of labor since fetal descent should be promoted by gravity as well as by better alignment between the 
axis of pushing and that of the birth canal $[51,52,53]$. Four meta-analyses [54-57] have been published about the effect of vertical compared with horizontal positions during the second stage of labor, but they do not include results about oxytocin use for each.

Two randomized trials of the effect of vertical and horizontal positions during the passive (descent) phase of the second stage of labor in nulliparas did describe oxytocin use, however [58, 59]. The first study by Golara et al., published in 2002, focused on women with ambulatory epidural analgesia and sought to compare walking vs supine or seated positions [58]. The authors found no statistically significant difference in oxytocin use during the second stage of labor $(n=66$, intervention group $16 \%$ vs control group $9 \%)$. This study had numerous methodological problems since the allocation groups were not balanced (41 vs 25). Moreover, co-interventions during the first stage were not reported (especially positions), except for oxytocin use (first stage: intervention 56\%, control 36\% NS) (LE3). The other trial, published by Downe et al. in 2004, looked at the effect of lateral vs seated positions during the passive phase of the second stage among women with epidural analgesia. Nonetheless, although oxytocin use was described, the point during labor at which it began was not reported [59].

Overall, the use of a vertical or horizontal position during the second stage of labor does not appear to affect recourse to oxytocin (LE3).

\section{Immersion in water}

A Cochrane database meta-analysis published in 2011 studied the impact of immersion in water on maternal and neonatal outcomes [60]. This meta-analysis included 12 randomized trials with nulliparous and parous women with singleton pregnancies.

Five of the studies compared immersion and non-immersion during the first stage of labor for oxytocin use. There was no difference in recourse to oxytocin during labor $(n=1125$, RR 0.64 , 95\% CI 0.32-1.28) (LE2). We found no distinction between the nulliparous and 
parous women for indications for oxytocin, diagnostic methods at the onset of labor, or for support during labor.

A single study in this meta-analysis compared early (before $5 \mathrm{~cm}$ dilation) and late (after $5 \mathrm{~cm}$ ) immersion in water during the first stage [61]. The women were nulliparous or parous, at low risk and in spontaneous labor. The authors found greater oxytocin use in the early than in the late group ( $\mathrm{n}=200$; RR $1.90,95 \%$ CI $1.35-2.68)$ with no other differences in obstetric or neonatal outcomes (LE2). On the other hand, this meta-analysis also included a randomized trial that compared immersion at $6-7 \mathrm{~cm}$ of dilation vs no immersion and found no difference in oxytocin use between the two groups ( $\mathrm{n}=108$, RR $0.83,95 \%$ CI $0.51-1.33$ ).

Overall, immersion in water during the first stage of spontaneous labor does not appear to influence oxytocin use (LE2).

\section{Infusion, hydration, eating}

Different cultures have different policies about eating food and about the administration of intravenous solutions.

\section{Intravenous infusion during labor}

A Cochrane database meta-analysis searched for studies about the administration of an intravenous infusion to reduce the duration of labor in nulliparas (19 studies, $n=3130$ ) [62]. It did not study the effect of this practice on oxytocin use during labor.

Seven randomized trials assessed the value of an intravenous infusion for hydration during labor on recourse to oxytocin [63-69]. These trials included nulliparas at term or at least at a gestational age $\geq 36$ weeks in spontaneous labor. They compared two or more groups with intravenous infusion of Ringer Lactate ${ }^{\circledR}$-type solutions (except for one study with a glucose-saline solution). All of the studies included an intervention group, each individual receiving an intake of $250 \mathrm{~mL} / \mathrm{h}(240 \mathrm{ml} / \mathrm{h}$ for one study) and one or more control groups (125 mL/h or $120 \mathrm{~mL} / \mathrm{h}$ for one study or smaller IV intake together with oral intake). The 
results for oxytocin were contradictory; some authors found no difference between the groups $[64,66,68,69]$, while others found reduced recourse to oxytocin in the group with an intravenous solution of $250 \mathrm{~mL} / \mathrm{h}[63,65,67]$ (LE2).

These contradictory results prevent us from reaching a definitive conclusion about the effect of intravenous intake during labor on recourse to oxytocin.

\section{Oral hydration and solid food during labor}

We identified 2 meta-analyses of randomized trials on this topic. The first Cochrane database meta-analysis, published in 2013, studied oral restriction of food and water during labor [70]. The authors included 5 randomized trials that compared different interventions restricting oral intake vs free oral intake: 2 studies compared a restrictive policy including the possibility of drinking water to a policy encouraging women to eat and drink during labor [71, 72]; 2 studies compared women who had only water with those who drank fluid carbohydrates during labor [73, 74]; and another compared a restrictive policy with no fluid intake to a policy allowing women to eat and drink as they chose during labor [75]. The authors found no difference in oxytocin use between women subject to the restrictive policies and those for whom oral intake was authorized $(n=3103$; RR 1.02, 95\% CI 0.95-1.09).

The second meta-analysis appeared in 2016. It sought to assess the impact on the progress of labor of oral intake of fluid carbohydrates [76]. The authors included 6 randomized trials comparing fluid carbohydrate intake vs a placebo or water intake during labor. Two of the trials authorized women to eat $[77,78]$. The authors found no difference in oxytocin use during labor ( $\mathrm{n}=516$; RR 1.03, 95\% CI 0.92-1.16) (LE2).

The most recent guidelines of the SFAR (French Society of Anesthesia and Resuscitation) authorized woman in labor with perimedullary (epidural or spinal) analgesia to drink non-particulate fluids, except for women with diabetes, morbid obesity, or a foreseeable cesarean [79]. 
These contradictory results prevent us from reaching a definitive conclusion about the effect of intravenous intake during labor on recourse to oxytocin (LE2). Neither oral hydration nor solid food during labor appear to affect oxytocin use (LE2).

\section{Alternative medicine}

There are a variety of different approaches to help parturients manage their pain during labor. As their use continues to grow, it would be interesting to know whether or not they modulate oxytocin use. The Cochrane Library has even devoted an entire systematic review to compiling all of the existing meta-analyses on the subject [80]. They cover a wide variety of different interventions: relaxation, massage, acupuncture, TENS (transcutaneous electric neurostimulation), injection of sterile water, hypnosis, and aromatherapy. We therefore sought to determine if some of these techniques (hypnosis, relaxation, and acupuncture) could modulate oxytocin use during labor.

\section{Hypnosis}

Two meta-analyses have examined the effects of hypnosis [81, 82]. The Cochrane metaanalysis, published in 2012, included only one randomized trial that assessed oxytocin recourse in both groups [83]. The authors of this randomized trial sought to assess the effect of antenatal hypnosis sessions on the use of epidural analgesia. This study included both nulliparous and parous women giving birth after 34 weeks of gestation, randomized into 3 antenatal preparation groups: one that followed an extensive antenatal preparation planned in the protocol (preparation with live sessions of hypnosis and hypnosis CDs at home), another with standard preparation sessions with the hypnosis $\mathrm{CD}$, and a control group with only standard antenatal preparation (no mention of hypnosis). They found no effect on oxytocin use in the hypnosis groups (the $\mathrm{CD}+$ hypnosis group and the $\mathrm{CD}$-only group) between each 
other or together compared with the control group (respectively, $n=305$, RR $1.00,95 \%$ CI 0.75-1.35; n=294, RR 1.00, 95\% CI 0.74-1.35) (LE3).

An earlier meta-analysis, published in 2004, found that oxytocin use was lower for the women who had had hypnosis ( $\mathrm{n}=102$, RR 0.31, 95\% CI 0.18-0.52) [82] (LE3). Nonetheless this meta-analysis included a very small number of women, and the studies considered in this publication were excluded from the Cochrane analysis because they combined induction and oxytocin use during labor.

We found two randomized trials that have appeared since, but the authors did not report oxytocin use in their results $[84,85]$.

Overall, we did not find that antenatal preparation with hypnosis sessions affected oxytocin use (LE3).

\section{Relaxation}

We found 2 meta-analyses of relaxation [86, 87]. The first focused on manual relaxation techniques, such as massage or reflexotherapy [86]. In the two studies considered by these authors that described oxytocin use, the intervention was based on teaching massage techniques to the woman's partner to use during labor. These manual relaxation techniques did not affect oxytocin use ( $\mathrm{n}=105$, RR 1.09, 95\% CI 0.40-2.97] (LE3). Another recent randomized trial examined massage use during labor, but did not report on oxytocin use [88].

The other meta-analysis looked at relaxation techniques including sophrology, yoga, and self-meditation [87]. The authors identified only two studies that reported oxytocin use during labor as an outcome. The first dates back to 1979 and was not included [89]. The second sought to assess the effect of antenatal yoga sessions on the course of labor and on pain during labor. The authors described the different treatments used to accelerate labor (oxytocin, amniotomy, and oxytocin+amniotomy) but without specifying their indications. 
For oxytocin use only, they found no differences between the intervention and control groups (n=66, RR 0.76, 95\% CI 0.45-1.31) [87, 90] (LE3).

The relaxation techniques used during labor, manual or reflexive, do not appear to reduce the need for oxytocin (LE3).

\section{Acupuncture and acupressure}

None of the trials identified concerned the use of acupuncture as treatment for labor dystocia. The studies selected aimed to examine the effect of acupuncture (or acupressure) on pain and the course of labor.

We found one meta-analysis of randomized trials published in the Cochrane database in 2011 and 6 randomized trials published since then [91-97]. Of the 6 trials, only 4 reported oxytocin use [94-97]. The meta-analysis by Smith et al. included 13 randomized trials including 9 about acupuncture (manual or electroacupuncture) and 4 about acupressure, with both nulliparous and parous women [91]. There were various methodological problems or inclusion biases in these studies (including non-comparable groups, wrongful inclusion, postrandomization exclusion, and failure to perform the allocated intervention). The authors found no differences in oxytocin use between the women who had acupuncture during labor and those who had a placebo ( 2 trials, $n=358$, RR $0.62,95 \%$ CI $0.15-2.52$ ), or those who had standard care ( 2 trials, $\mathrm{n}=506$, RR $0.88,95 \%$ CI $0.72-1.08$ ) or small injections of sterile water (1 trial, n=128, RR 1.16, 95\% CI 0.85-1.58) (LE2).

We found 3 other randomized trials that have appeared since the last meta-analysis; they evaluated electroacupuncture vs usual management [94-96]. One trial compared points SP6 and BX2 [94], another looked at several different acupuncture points [96], and a third focused on points T10-L3 and BL32 [95]. None of these three sets of authors found any difference in oxytocin use between the women having electroacupuncture and those with usual management (LE2). 
The results for the studies of acupressure could not be pooled in the meta-analysis because they had different control groups (placebo and routine care). We will therefore discuss each article individually. There were 4 randomized trials of acupressure during labor [96-99]. The interventions and the groups analyzed were different in each study (LE2). That is, 3 articles studied acupressure vs routine care [96-98], 3 compared it with light touch, a placebo (touching the area targeted by the study) [97-99], and one studied acupressure vs electroacupuncture [96]. Three studies assessed stimulation of the SP point6 [97-99] and one tested several acupuncture points [96]. One study included more women with ruptured membranes in the intervention group than in the placebo group (50\% vs $26.9 \%)$, but the authors failed to adjust for this difference [97]. Although they reported less recourse to oxytocin in the intervention group than in the touch placebo group, the finding must be interpreted in light of the substantial difference in the number of women with ruptured membranes in the intervention group $(P=0.017)$ [97]. Among the other 3 studies, only one found that the intervention group used oxytocin, both less often than the placebo group and less total oxytocin ( $\mathrm{n}=120$, respectively $P=0.017$ and $P=0.003)$ [100]. The other 2 studies found no differences in oxytocin use [96, 97].

We found no studies of the effect of acupuncture on labor dystocia.

Overall, neither acupuncture nor acupressure during labor appears to influence oxytocin use (LE2).

\section{Pharmacological products}

A Cochrane meta-analysis examined the effects of antispasmodic agents during labor [100]. None of the substances tested, however, is used in France (valethamate bromide, drotaverine hydrochloride, hyoscine butyl bromide, rociverine, and camylofin dihydrochloride). 
We found only one randomized trial that studied phloroglucinol but it did not report oxytocin use in its results [101]. Our literature search found only articles published before 1970.

Several studies looked for and found an in vitro myorelaxant effect of magnesium on myometrial cells. This effect was also found in myometrial cells treated with oxytocin $[102$, 103]. Nonetheless, we found no in vivo studies of the effect of magnesium administration on oxytocin use or on labor dystocia, regardless of the cause.

Overall, the current scientific data do not allow us to define the potential utility of myorelaxants in labor dystocia during spontaneous labor (LE4).

\section{Conclusions about other interventions modulating oxytocin use}

No scientific evidence justifies the recommendation of any of the following methods for the sole purpose of limiting oxytocin use during labor: maternal position during the first or second stages of labor (grade C), immersion in water during the first stage (grade B), intravenous infusion, oral hydration, or solid food (grade B), antenatal preparation with hypnosis sessions (grade C), use of relaxation techniques (grade C), acupuncture or acupressure (grade B), or the use of muscle-relaxant agents (professional consensus).

\section{General conclusion}

Few co-interventions during labor appear to modulate oxytocin use or the onset of labor dystocia, except for a routine early amniotomy, which does reduce recourse to oxytocin. Nonetheless, this routine early amniotomy does not improve maternal or neonatal outcomes and may even increase the cesarean rate. In cases of labor dystocia during the active phase, an amniotomy is recommended before the administration of oxytocin (professional consensus). 
The other co-interventions, that is, positions, immersion in water, oral hydration or infusion, hypnosis, relaxation, acupuncture, and acupressure, are not recommended for the purpose of limiting oxytocin use. Only continuous support during labor must be encouraged, since it appears to improve maternal and neonatal outcomes.

\section{Acknowledgements}

We thank Corinne Dupont and the workgroup for their helpful advice and the reading group for taking the time to improve this article.

Funding: This work was supported by the College National des Sages-femmes de France.

\section{Conflicts of interests}

The authors report they have no conflict of interests. 


\section{References}

[1] Den Hertog CEC, De Groot A, Van Dongen PWJ. History and use of oxytocics. Eur J Obstet Gynecol Reprod Biol. 2001;94:8-12.

[2] Gaucher L, Le Ray C. Oxytocin administration during spontaneous labor: guidelines for clinical practice. Chapter 2: indications of oxytocin according the first and second stages of spontaneous labor. J Gynecol Obstet Hum Reprod (2017) [This issue]

[3] O’Driscoll K, Jackson RJA, Gallagher JT. Prevention of Prolonged Labour. Br Med J. 1969;2: 477-480.

[4] O’Driscoll K, Stronge JM, Minogue M. Active management of labour. Br Med J. 1973;3: $135-7$.

[5] Fraser W, Vendittelli F, Krauss I, Bréart G. Effects of early augmentation of labour with amniotomy and oxytocin in nulliparous women: a meta-analysis. BJOG. 1998;105: 189-94.

[6] Wei S, Wo BL, Qi HP, Xu H, Luo ZC, Roy C et al. Early amniotomy and early oxytocin for prevention of, or therapy for, delay in first stage spontaneous labour compared with routine care. Cochrane Database of Systematic Reviews 2013, Issue 8. Art. No.: CD006794. DOI: 10.1002/14651858.CD006794.pub4. 
[7] Brown HC, Paranjothy S, Dowswell T, Thomas J. Package of care for active management in labour for reducing caesarean section rates in low-risk women. Cochrane Database Syst Rev. 2013;9:CD004907.

[8] Sadler LC, Davison T, McCowan LME. A randomised controlled trial and meta-analysis of active management of labour. BJOG. 2000;107: 909-15.

[9] Hunter DJS. Dystocia: where do we stand with the diagnosis and treatment? Contemp Rev Obstet Gynaecol. 1993;5: 5-8.

[10] Bidgood KA, Steer PJ. A randomized control study of oxytocin augmentation of labour. 1.Obstetric outcome. BJOG. 1987; 94: 512-7.

[11] Hemminki E, Lenck M, Saarikoski S, Henriksson L. Ambulation vs oxytocin in protacted labour: a pilot study. Eur J Obstet Gynecol Reprod Biol. 1985; 20: 199-208.

[12] Blanch G, Walkinshaw S, Alfirevic Z. Dysfunctional labour: a randomised trial. BJOG. 1998;105:117-20.

[13] Cluett ER, Pickering RM, Brooking JI. An investigation into the feasibility of comparing three management options (augmentation conservative and water) for nulliparae with dystocia in the first stage of labour. Midwifery. 2001;17:35-43. 
[14] Cluett ER, Pickering RM, Getliffe K, Saunders NJ. Randomised controlled trial of labouring in water compared with standard of augmentation for management of dystocia in first stage of labour. Br Med J. 2004;328:314-8.

[15] Garmi G, Salim R, Kadan I, Zafran N, Shalev E, Nachum Z. Augmentation of labor for prolonged latent phase at term: a randomized comparison between amniotomy, oxytocin or both. Am J Obstet Gynecol. 2008;199:S58.

[16] Nachum Z, Garmi G, Kadan Y, Zafran N, Shalev E, Salim R. Comparison between amniotomy, oxytocin or both for augmentation of labor in prolonged latent phase: a randomized controlled trial. Reprod Biol Endocrinol .2010;8:136.

[17] Rogers R, Gilson G, Kammerer-Doak D. Epidural analgesia and active management of labor: effects on length of labor and mode of delivery. Obstet Gynecol.1999;93: 995-8.

[18] Rogers R, Gilson GJ, Miller AC, Izquierdo LE, Curet LB, Qualls CR. Active management of labor: does it make a difference? Am J Obstet Gynecol. 1997;177:599-605.

[19] Rogers RG, Gardner MO, Tool KJ, Ainsley J, Gilson G. Active management of labor: a cost analysis of a randomized controlled trial. West J Med. 2000;172:240-3.

[20] Serman F, Benavides C, Sandoval J, Pazols R, Bernedo J, Fuenzalida R et al. Active labour management in primiparas. Prospective study. Rev Chil Obstet Ginecol. 1995;60: 6-11. 
[21] Snehlata, Sawant V. Comparison of active management of labour versus 'traditional' approach. 54th All India Congress of Obstetrics and Gynaecology,2011 Jan 5-9;Hyderabad, Andhra Pradesh, India; 2011. p.246-7.

[22] Somprasit C, Tanprasertkul C, Kamudhamas A. Reducing cesarean delivery rates: an active management labor program in a setting with limited resources. J Med Assoc Thai. 2005;88:20-5.

[23] Tabowei TO, Oboro VO. Active management of labour in a district hospital setting. J Obstet Gynaecol. 2003;23: 9-12.

[24] Bréart G, Mlika-Cabane N, Kaminski M, Alexander S, Herruzo-Nalda A, Mandruzzato P et al. Evaluation of different policies for the management of labour. Early Hum Dev. 1992;29: $309-12$.

[25] Lopez-Zeno JA, Peaceman AM, Adashek JA, Socol ML. A controlled trial of a program for the active management of labor. N Engl J Med. 1992;326:450-4.

[26] Lopez-Zeno JA, Peaceman AM, Socol ML. Active management of labor (AMOL) - an evaluation of its efficacy. Am J Obstet Gynecol. 1991;164:306.

[27] Beranger R, Chantry A. Oxytocin administration during spontaneous labor: guidelines for clinical practice. Chapter 1: definition and characteristics of the normal and abnormal labor. J Gynecol Obstet Hum Reprod (2017) [This issue] 
[28] Smyth RMD, Markham C, Dowswell T. Amniotomy for shortening spontaneous labour.

Cochrane Database of Systematic Reviews 2013, Issue 6. Art. No.: CD006167. DOI: 10.1002/14651858.CD006167.pub4.

[29] Goffinet F, Fraser W, Marcoux S, Bréart G, Moutquin JM, Daris M. Early amniotomy increases the frequency of fetal heart rate abnormalities. Amniotomy Study Group. BJOG. 1997;104:548-53.

[30] American College of Obstetricians and Gynecologists; Society for Maternal-Fetal Medicine. Obstetric care consensus no. 1: safe prevention of the primary cesarean delivery. Obstet Gynecol. 2014;123:693-711.

[31] National Institute for Health and Care Excellence. Intrapartum care: care of healthy women and their babies during childbirth, www.nice.org.uk/guidance/cg190; 2014 [accessed 28.12.2016].

[32] Brisson-Carroll G, Fraser W, Bréart G, Krauss I, Thornton J. The effect of routine early amniotomy on spontaneous labor: a meta-analysis. Obstet Gynecol. 1996;87:891-6.

[33] Fraser WD, Turcot L, Krauss I, Brisson-Carrol G. Amniotomy for shortening spontaneous labour. Cochrane Database Syst Rev. 2007 18:CD000015.

[34] Mikki N, Wick L, Abu-Asab N, Abu-Rmeileh NM. A trial of amniotomy in a Palestinian hospital. J Obstet Gynaecol. 2007;27:368-73. 
[35] Ajada MA, Kuti O, Orji EO, Ogunniyi SO, Sule SS. The effect of amniotomy on the outcome of spontaneous labour in uncomplicated pregnancy. J Obstet Gynaecol. 2006;26:631-4.

[36] Shobeiri F, Tehranian N, Nazari M. Amniotomy in labor. Int J Gynecol Obstet. 2007;96:197-8.

[37] Barrett JFR, Savage J, Phillips K, Lilford RJ. Randomized trial of amniotomy in labour vs the intention to leave membranes intact until the second stage. Br J Obstet Gynaecol 1992;99:5-10.

[38] Guerresi E, Gori G, Beccari A, Farro M, Mazzani C. Influence of spasmolytic treatment and amniotomy on delivery times: A factorial clinical trial. Clinical Ther. 1981;3:382-8.

[39] Laros RK, Work BA, Witting WC. Amniotomy during the active phase of labor. Obstet Gynecol. 1972;39:702-4.

[40] Ghafarzadeh M, Moeininasab S, Namdari M. Effect of early amniotomy on dystocia risk and cesarean delivery in nulliparous women: a randomized clinical trial. Arch Gynecol Obstet. 2015;292: 321-5.

[41] Cardozo L, Pearce JM. Oxytocin in active-phase abnormalities of labor: a randomized study. Obstet Gynecol. 1990;75: 152-7. 
[42] Rouse DJ, McCullough C, Wren AL, Owen J, Hauth JC. Active-phase labor arrest: a randomized trial of chorioamnion management. Obstet Gynecol. 1994;83:937-40.

[43] Hodnett ED, Gates S, Hofmeyr GJ, Sakala C. Continuous support for women during childbirth. Cochrane Database Syst Rev. 2013;7:CD003766.

[44] Chaillet N, Belaid L, Crochetière C, Roy L, Gagné G-P, Moutquin JM et al. Nonpharmacologic approaches for pain management during labor compared with usual care: a meta-analysis. Birth. 2014;41:122-37.

[45] WHO. Recommendations for Augmentation of Labour. Geneva: World Health Organization; 2014.

[46] Society of Obstetricians and Gynaecologists of Canada. Joint Policy Statement on Normal Childbirth. J Obstet Gynaecol Can. 2008; 30(12):1163 - 65 . http://dx.doi.org/10.1016/S1701-2163(16)34029-4

[47] Zhang J, Bernasko JW, Leybovich E, Fahs M, Hatch MC. Continuous labor support from labor attendant for primiparous women: a meta-analysis. Obstet Gynecol. 1996;88:739-44.

[48] Scott KD, Berkowitz G, Klaus M. A comparison of intermittent and continuous support during labor: a meta-analysis. Am J Obstet Gynecol. 1999;180:1054-9. 
[49] Sosa R, Kennell J, Klaus M, Robertson S, Urrutia J. The effect of a supportive companion on perinatal problems, length of labor, and mother-infant interaction. N Engl J Med. 1980;303:597-600.

[50] Lawrence A, Lewis L, Hofmeyr GJ, Dowswell T, Styles C. Maternal positions and mobility during first stage labour. Cochrane Database Syst Rev. 2009;2 :CD003934.

[51] Liddell HS, Fisher PR. The birthing chair in the second stage of labour. Aust N Z J Obstet Gynaecol. 1985;25:65-8.

[52] Malinas Y, Favier M. Mécanique obstétricale. Paris: Ed Masson; 1979.

[53] Berghella V, Baxter JK, Chauhan SP. Evidence-based labor and delivery management. Am J Obstet Gynecol. 2008;199:445-54.

[54] Roberts CL, Algert CS, Cameron CA, Torvaldsen S. A meta-analysis of upright positions in the second stage to reduce instrumental deliveries in women with epidural analgesia. Acta Obstet Gynecol Scand.2005;84:794-8.

[55] Vendittelli F. Le type de poussée et la position maternelle pendant le 2ème stade du travail ont-ils un impact, sur les issues obstétricales ou néonatales ? 42ème Journées Nationales de la Société Française de Médecine Périnatale,2012 Oct. 17-19; Montpellier, Paris: Springer, 2012.p.135-53. 
[56] Gupta JK, Hofmeyr GJ, Shehmar M. Position in the second stage of labour for women without epidural anaesthesia. Cochrane Database of Systematic Reviews. 2012; 5. CD002006.

[57] Kemp E, Kingswood CJ, Kibuka M, Thornton JG. Position in the second stage of labour for women with epidural anaesthesia. Cochrane Database of Systematic Reviews. 2013;1: CD008070.

[58] Golara M, Plaat F, Shennan AH. Upright versus recumbent position in the second stage of labour in women with combined spinal-epidural analgesia. Int J Obstet Anesth. 2002;11:19 -22 .

[59] Downe S, Gerrett D, Renfrew MJ. A prospective randomised trial on the effect of position in the passive second stage of labour on birth outcome in nulliparous women using epidural analgesia. Midwifery. 2004;20:157-68.

[60] Cluett ER, Burns E. Immersion in water in labour and birth. Cochrane Database of Systematic Reviews 2009, Issue 2. Art. No.: CD000111. DOI: 10.1002/14651858.CD000111.pub3.

[61] Eriksson M, Mattson L, Ladfors L. Early or late bath during the first stage of labour: a randomised study of 200 women. Midwifery 1997;13:146-8.

[62] Dawood F, Dowswell T, Quenby S. Intravenous fluids for reducing the duration of labour in low risk nulliparous women. Cochrane Database of Systematic Reviews 2013; 6: CD007715. 
[63] Eslamian L, Marsoosi V, Pakneeyat Y. Increased intravenous fluid intake and the course of labor in nulliparous women. Int J Gynaecol Obstet. 2006;93:102-5.

[64] Coco A, Derksen-Schrock A, Coco K, Raff T, Horst M, Hussar E. A randomized trial of increased intravenous hydration in labor when oral fluid is unrestricted. Fam Med. 2010;42:52-6.

[65] Alavi M, Talaie Rad Z, Dadgar S. Assessment of the effects of increased intravenous hydration on the course of labor in nulliparous term pregnancies. Med J Islam Repub Iran. 2005;18:289-292

[66]. Kavitha A, Chacko KP, Thomas E, Rathore S, Christoper S, Biswas B et al. A randomized controlled trial to study the effect of IV hydration on the duration of labor in nulliparous women. Arch Gynecol Obstet. 2012;285:343-6.

[67] Direkvand-Moghadam A, Rezaeian M. Increased intravenous hydration of nulliparas in labor. Int J Gynaecol Obstet. 2012;118:213-5.

[68] Edwards RK, Reed CA, Villano KS, Holmes JL, Tong S, Davies JK. Effect of hydration on spontaneous labor outcomes in nulliparous pregnant women: a multicenter randomized controlled trial comparing three methods. Am J Perinatol. 2014;31:455-62. 
[69] Garite TJ, Weeks J, Peters-Phair K, Pattillo C, Brewster WR. A randomized controlled trial of the effect of increased intravenous hydration on the course of labor in nulliparous women. Am J Obstet Gynecol. 2000;183:1544-8.

[70] Singata M, Tranmer J, Gyte GML. Restricting oral fluid and food intake during labour. Cochrane Database of Systematic Reviews. 2013; 8: CD003930.

[71] O'Sullivan G, Liu B, Hart D, Seed P, Shennan A. Effect of food intake during labour on obstetric outcome: randomised controlled trial. BMJ 2009;338:784.

[72] Scrutton MJ, Metcalfe GA, Lowy C, Seed PT, O'Sullivan G. Eating in labour: a randomised controlled trial assessing the risks and benefits. Anaesthesia 1999;54:329-34.

[73] Kubli M, Scrutton MJ, Seed PT, O'Sullivan G. An evaluation of isotonic "sport drinks" during labor. Anesth Analg. 2002;94:404-8.

[74] Scheepers HCJ, Thans MCJ, de Jong PA, Essed GGM, Le Cessie S Kanhai HH. A double-blind, randomised, placebo controlled study on the influence of carbohydrate solution intake during labour. BJOG. 2002;109:178-81.

[75] Tranmer JE, Hodnett ED, Hannah ME, Stevens BJ. The effect of unrestricted oral carbohydrate intake on labor progress. J Obstet Gynecol Neonatal Nurs. 2005;34:319-28. 
[76] Malin GL, Bugg GJ, Thornton J, Taylor MA, Grauwen N, Devlieger R et al. Does oral carbohydrate supplementation improve labour outcome? A systematic review and individual patient data meta-analysis. BJOG. 2016;123:510-7.

[77] Ciura N, Vandevelde M, Offeciers H, Jorissen G, Corthout C, Devlieger R. The effect of isotonic drinks during labour on pregnancy outcome: a randomized controlled trial. Reprod Sci. 2012;19 Suppl:305A.

[78] Kardel KR, Henriksen T, Iversen PO. No effect of energy supply during childbirth on delivery outcomes in nulliparous women: a randomised, double-blind, placebo-controlled trial. J Obstet Gynaecol. 2010;30:248-52.

[79] Société Française d'Anesthésie et de Réanimation. [Les blocs périmédullaires chez l'adulte]. Ann Fr Anesth Reanim. 2007;26:720-52.

[80] Jones L, Othman M, Dowswell T, Alfirevic Z, Gates S, Newburn M et al. Pain management for women in labour: an overview of systematic reviews. Cochrane Database of Systematic Reviews 2012, Issue 3.

[81] Madden K, Middleton P, Cyna AM, Matthewson M, Jones L. Hypnosis for pain management during labour and childbirth. Cochrane Database of Systematic Reviews 2012, Issue 11. Art. No.: CD009356.

[82] Cyna AM, McAuliffe GL, Andrew MI. Hypnosis for pain relief in labour and childbirth: a systematic review. Br J Anaesth. 2004;93:505-11. 
[83] Cyna AM, Crowther CA, Robinson JS, Andrew MI, Antoniou G, Baghurst P. Hypnosis antenatal training for childbirth: a randomised controlled trial. BJOG. 2013;120:1248-59.

[84] Downe S, Finlayson K, Melvin C, Spiby H, Ali S, Diggle P et al. Self-hypnosis for intrapartum pain management (SHIP) in pregnant nulliparous women: a randomised controlled trial of clinical effectiveness. BJOG 2015;122:1226-34.

[85] Werner A, Uldbjerg N, Zachariae R, Nohr EA. Effect of self-hypnosis on duration of labor and maternal and neonatal outcomes: a randomized controlled trial. Acta Obstet Gynecol Scand. 2013;92:816-23.

[86] Smith CA, Levett KM, Collins CT, Jones L. Massage, reflexology and other manual methods for pain management in labour. Cochrane Database of Systematic Reviews 2012, Issue 2. Art. No.: CD009290.

[87] Smith CA, Levett KM, Collins CT, Crowther CA. Relaxation techniques for pain management in labour. Cochrane Database of Systematic Reviews 2011, Issue 12. Art. No.: CD009514.

[88] Silva Gallo RB, Santana LS, Jorge Ferreira CH, Marcolin AC, PoliNeto OB, Duarte G et al. Massage reduced severity of pain during labour: a randomised trial. J Physiother. 2013;59:109-16. 
[89] Dolcetta G, Azzini V, Zacche G, Tansella CZ, Bertagni P, Siani R. Traditional and respiratory autogenic training in psychoprophylaxis for childbirth. A controlled study on psychological and clinical effects in primiparous. Proceedings of 5th International Congress on Psychosomatic Medicine in Obstetrics and Gynaecology, "Emotion and Reproduction”,1977 Nov. 13-19; Rome, London: Academic Press; 1979.p.929-36.

[90] Chuntharapat S, Petpichetchian W, Hatthakit U. Yoga during pregnancy: effects on maternal comfort, labor pain and birth outcomes. Complement Ther Clin Pract. 2008;14:10515

[91] Smith CA, Collins CT, Crowther CA, Levett KM. Acupuncture or acupressure for pain management in labour. Cochrane Database of Systematic Reviews 2011, Issue 7. Art. No.: CD009232.

[92] Vixner L, Martensson LB, Schytt E. Acupuncture with manual and electrical stimulation for labour pain: a two month follow up of recollection of pain and birth experience. BMC Complement Altern Med. 2015;15:180.

[93] Mucuk S, Baser M. Effects of noninvasive electroacupuncture on labour pain and duration. J Clin Nurs. 2014;23:1603-10.

[94] Dong C, Hu L, Liang F, Zhang S. Effects of electro-acupuncture on labor pain management. Arch Gynecol Obstet. 2015;291:531-6. 
[95] Liu Y, Xu M, Che X, He J, Guo D, Zhao G et al. Effect of direct current pulse stimulating acupoints of JiaJi (T10-L3) and Ciliao (BL 32) with Han's Acupoint Nerve Stimulator on labour pain in women: a randomized controlled clinical study. J Tradit Chin Med. 2015;35:620-5.

[96] Vixner L, Schytt E, Stener-Victorin E, Waldenström U, Pettersson H, Mårtensson LB. Acupuncture with manual and electrical stimulation for labour pain: a longitudinal randomised controlled trial. BMC Complement Altern Med. 2014;14:187.

[97] Mafetoni RR, Shimo AK. Effects of acupressure on progress of labor and cesarean section rate: randomized clinical trial. Rev Saude Publica. 2015;49:9.

[98] Hjelmstedt A, Shenoy ST, Stener-Victorin E, Lekander M, Bhat M, Balakumaran L et al. Acupressure to reduce labor pain: a randomized controlled trial. Acta Obstet Gynecol Scand. 2010;89:14539.

[99] Kashanian M, Shahali S. Effects of acupressure at the Sanyinjiao point (SP6) on the process of active phase of labor in nulliparas women. J Matern Fetal Neonatal Med. 2010;23:638 41.

[100] Rohwer AC, Khondowe O, Young T. Antispasmodics for labour. Cochrane Database of Systematic Reviews 2013, Issue 6. Art. No.: CD009243.

[101] Tabassum S, Afridi B, Aman Z. Phloroglucinol for acceleration of labour: double blind, randomized controlled trial. J Pak Med Assoc. 2005;55:270. 
[102] Tica VI, Tica AA, Carlig V, Banica OS. Magnesium ion inhibits spontaneous and induced contractions of isolated uterine muscle. Gynecol Endocrinol. 2007;23:368-72.

[103] Tang YY, Du Y, Ni J, Ma YS, Lin XM, Zhou J. Relaxant effects of metoclopramide and magnesium sulfate on isolated pregnant myometrium: an in vitro study. Int $\mathrm{J}$ Obstet Anesth. 2014;23:131-7. 